\section{Physical activity in pregnancy and adverse birth outcomes}

\section{Atividade física em gestantes e desfechos perinatais adversos ao nascimento}

\section{Actividad física en gestantes y resultados perinatales adversos al nacimiento}

Adriana Sousa Rêgo 1

Maria Teresa Seabra Soares de Britto e Alves 1 Rosângela Fernandes Lucena Batista 1 Cecília Cláudia Costa Ribeiro 1 Heloísa Bettiol 2 Viviane Cunha Cardoso 2 Marco Antonio Barbieri 2 Flávia Helen Furtado Loureiro 1 Antonio Augusto Moura da Silva 1

doi:10.1590/0102-311X00086915

\begin{abstract}
This study focused on the association between physical activity in the second trimester of pregnancy and adverse perinatal outcomes: low birth weight $(L B W)$, preterm birth $(P T B)$, and intrauterine growth restriction (IUGR). The study used a sample from the BRISA cohort, São Luís, Maranhão State, Brazil, which included women with singleton pregnancy, gestational age from 22 to 25 weeks confirmed by obstetric ultrasound performed at $<20$ weeks, and re-interviewed in the first 24 hours postpartum ( $n=1,380)$. Level of physical activity was measured by the International Physical Activity Questionnaire (IPAQ), short version, categorized as high, moderate, and low. A directed acyclic graph (DAG) was used to identify minimum adjustment to control confounding. High physical activity was not associated with $L B W(R R=0.94 ; 95 \% C I: 0.54-1.63), P T B(R R=0.86$; 95\%CI: 0.48-1.54), or IUGR ( $R R=0.80$; 95\%CI: 0.55-1.15). The results support the hypothesis that physical activity during pregnancy does not result in adverse perinatal outcomes.
\end{abstract}

Pregnancy; Motor Activity; Low Birth Weight Infant; Premature Infant

\author{
1 Universidade Federal do \\ Maranhão, São Luís, Brasil. \\ 2 Faculdade de Medicina de \\ Ribeirão Preto, Universidade \\ de São Paulo, Ribeirão Preto, \\ Brasil. \\ Correspondence \\ A. S. Rêgo \\ Universidade Federal do \\ Maranhão. \\ Rua Barão de Itapary 155, \\ São Luís, MA \\ 65020-070, Brasil. \\ adricefs@yahoo.com.br
}




\section{Introduction}

Low birth weight (LBW), preterm birth (PTB), and intrauterine growth restriction (IUGR) are associated with increased short- and long-term risks of morbidity and mortality 1,2. They also increase the risk of delayed neurological and cognitive development as well as non-communicable diseases (cardiovascular diseases and diabetes mellitus) in adulthood 3,4 .

There are various risk factors for adverse perinatal outcomes ranging from classical factors such as hypertension, diabetes, and obesity 5 to physical activity during pregnancy 6 .

The American College of Obstetrics and Gynecology (ACOG) recommends that women who were already physically active should continue their physical activity during pregnancy and encourages pregnant women to engage in at least 30 minutes of physical activity per day, three or more days per week, in the absence of clinical contraindications 7 .

Although physical activity is recommended because of its benefits for the prevention and treatment of cardiovascular diseases, gestational diabetes, and other chronic diseases, there is no consensus on the potential risks to the mother and fetus ${ }^{8}$. Vigorous physical activity can result in reduced blood flow to the fetus, with a consequent reduction in essential substrates for its growth, and may result in adverse perinatal outcomes 9,10.

Early systematic literature reviews yielded insufficient evidence on the risks and/or benefits of physical activity to the mother and fetus 8,11. A more recent systematic review concluded that there are still significant gaps in knowledge on the safety of intense physical activity for the fetus ${ }^{11}$. This insufficient evidence may be due to the methodological difficulty in measuring gestational physical activity and to small study samples 8,11 .

The current study thus aimed to investigate the association between physical activity in pregnant women and adverse perinatal outcomes (low birth weight, preterm birth, and intrauterine growth restriction).

\section{Methods}

\section{Study design}

This was a nested study in a cohort study entitled Etiological Factors for Preterm Birth and Consequences of Perinatal Factors for Children's Health: Birth Cohorts in Two Brazilian Cities (BRISA), conducted by the Federal University of Maran- hão (UFMA) in partnership with the University of São Paulo (USP), in two Brazilian municipalities, São Luís, Maranhão State, and Ribeirão Preto, São Paulo State.

The BRISA cohort data from the municipality of São Luís were used in the current study. This is a convenience cohort started during the prenatal period (PRENATAL BRISA), since it was not possible to draw a random sample, because no list of pregnant women was available. In 2009-2010, 1,447 pregnant women were recruited in the waiting room at their prenatal visit or for obstetric ultrasound at three major public maternity services and public and private ultrasound laboratories. Inclusion criteria were: singleton pregnancy and gestational age confirmed by obstetric ultrasound performed at less than 20 weeks gestational age. The women were then invited to attend the Clinical Research Center (CEPEC) to answer a questionnaire. The prenatal interviews took place from the 22nd to the 25th gestational week. At childbirth, 1,381 women (95.4\%) were re-interviewed in 2010-2011, with 4.6\% losses. One observation was excluded because of missing values on physical activity. The total sample for analysis amounted to 1,380 women. Methodological data have been published elsewhere 12 .

\section{Sample calculation}

It was estimated that a sample of 1,092 pregnant women would have $85 \%$ power to identify rates ratios $\geq 2.0$ between physical inactivity and adverse birth outcomes, assuming 6-10\% prevalence of LBW, PTB, and IUGR in women that are sedentary in the second trimester, a ratio of 1:1 between exposed and unexposed infants, and 5\% probability of type I two-tailed error. After a $25 \%$ increment to adjust for potential confounding, the minimum sample size was set at 1,365 pregnant women.

\section{Questionnaires}

The first questionnaire was used to establish the women's socio-demographic profile and pattern of physical activity. The second questionnaire was applied in the first 24 hours postpartum. The following variables were recorded at birth: maternal hypertension, diabetes mellitus, vaginal bleeding, urinary infection, illicit drug use, alcohol consumption, hospitalization during pregnancy, and maternal smoking. All variables were categorized as yes or no. Parity (primipara, 2 or more children) and type of delivery (vaginal, non-elective cesarean section, elective cesarean section) were also recorded. 
The target socio-demographic variables were maternal age categorized as younger than 20 years, 20 to 34 years, and 35 years or more. Maternal schooling was categorized as less than 5,5 to 8,9 to 11 , and 12 or more years of school. Occupation was classified as non-manual, skilled/ semiskilled manual, or unskilled manual/unemployed/students). Economic class was defined according to the Criterion of Economic Classification - Brazil, elaborated by the Brazilian Association of Research Companies (ABEP) to estimate the purchasing power of urban families, categorized as A/B (highest income and education, and most household assets), C (intermediate), or D/E (lowest income and education) 13. Married/living with a partner and living with children were both categorized as yes or no.

\section{Level of physical activity}

Physical activity was assessed using the International Physical Activity Questionnaire (IPAQ) short version ${ }^{14}$, validated for the Brazilian population by Matsudo et al. 15. This instrument is used to obtain data on any type of physical activity. Women were asked, referring to the previous seven days, on how many days they walked and did moderate or vigorous physical activity for at least 10 minutes at a time.

Physical activity was classified in three levels - high, moderate, and low - on the basis of frequency, duration of each activity, and energy expenditure as metabolic equivalents (MET)minutes/week. For walking, 1 MET $=3.3 \times$ time (minutes) $\mathrm{x}$ day; for moderate activity, $1 \mathrm{MET}=$ $4.0 \mathrm{x}$ time (minutes) $\mathrm{x}$ day, and for high activity, $1 \mathrm{MET}=8.0 \mathrm{x}$ time (minutes) $\mathrm{x}$ day. Total METminutes/week is calculated as the sum of partial MET-minutes/week 16.

Physical activity was considered high when practiced vigorously for at least three days, reaching at least 1,500 MET-minutes/week, or for at least seven days with any combination of walking, moderate or vigorous activity, reaching at least 3,000 MET-minutes/week. Moderate was defined as vigorous activity for at least $20 \mathrm{~min}$ utes for three or more days or moderate for five or more days and/or involving a walk of at least 30 minutes per day, or consisting of five or more days of a combination of walking, moderate activity, or vigorous activity reaching at least 600 MET-minutes/week. Low activity was defined as opposed to high or moderate levels of physical activity, < 600 MET-minutes/week 16.

\section{Outcome variables}

The dependent variables were: gestational age categorized in weeks as preterm (PTB $<37$ weeks) or term ( $\geq 37$ weeks); LBW $(<2,500 \mathrm{~g})$, and IUGR classified according to the birth weight ratio (BWR) proposed by Kramer ete al. 17, calculated by dividing the newborn's weight by the sexspecific median weight for gestational age from the Canadian curve ${ }^{18}$. Neonates were defined as not presenting IUGR when the BWR was $\geq 0.85$, and as presenting IUGR when BWR was $<0.8517$. Gestational age was estimated by two criteria, i.e., date of last menstruation (DLM) and obstetric ultrasound (OU) performed before 20 weeks gestational age (GA). When GA measured by DLM differed by more or less than 10 days from the value estimated by OU, GA was calculated by DLM; when GA differed by more than 10 days between these two indicators, it was estimated by OU 19 . Information on date and time of birth was obtained from the infant's medical records.

\section{Statistical analysis}

Data were analyzed using Stata, version 12.0 (StataCorp LP, College Station, USA). Descriptive analyses were performed with estimates of absolute and percent frequencies. Frequencies were compared between groups by the chi-square test. Associations between physical activity and three different outcomes (LBW, PTB, and IUGR) were estimated by Poisson multiple regression models with robust estimation of variance 20 . Rates ratios (RR) and 95\% confidence intervals $(95 \% \mathrm{CI})$ were used as measures of association. Physical activity was treated as an ordinal variable categorized in three levels: low, moderate, and high. Moderate physical activity was taken as the reference. Sensitivity analysis was also performed to check for consistency, where physical activity was treated as a continuous variable (minutes or MET-minutes/week) or divided into tertiles, quartiles, or quintiles. To check for possible non-linearity, a quadratic term was also added to the models, where physical activity was treated as a continuous variable.

A directed acyclic graph (DAG) was constructed to identify a minimum set of confounding adjustment in the DAGitty program (Figure 1) 21 . Interrelations between variables were constructed based on Takito \& Benicio's theoretical hierarchical model ${ }^{22}$. Models were then adjusted for maternal schooling, economic class, living with partner, and living with children.

The study was approved by the Institutional Review Board of the University Hospital of UFMA 


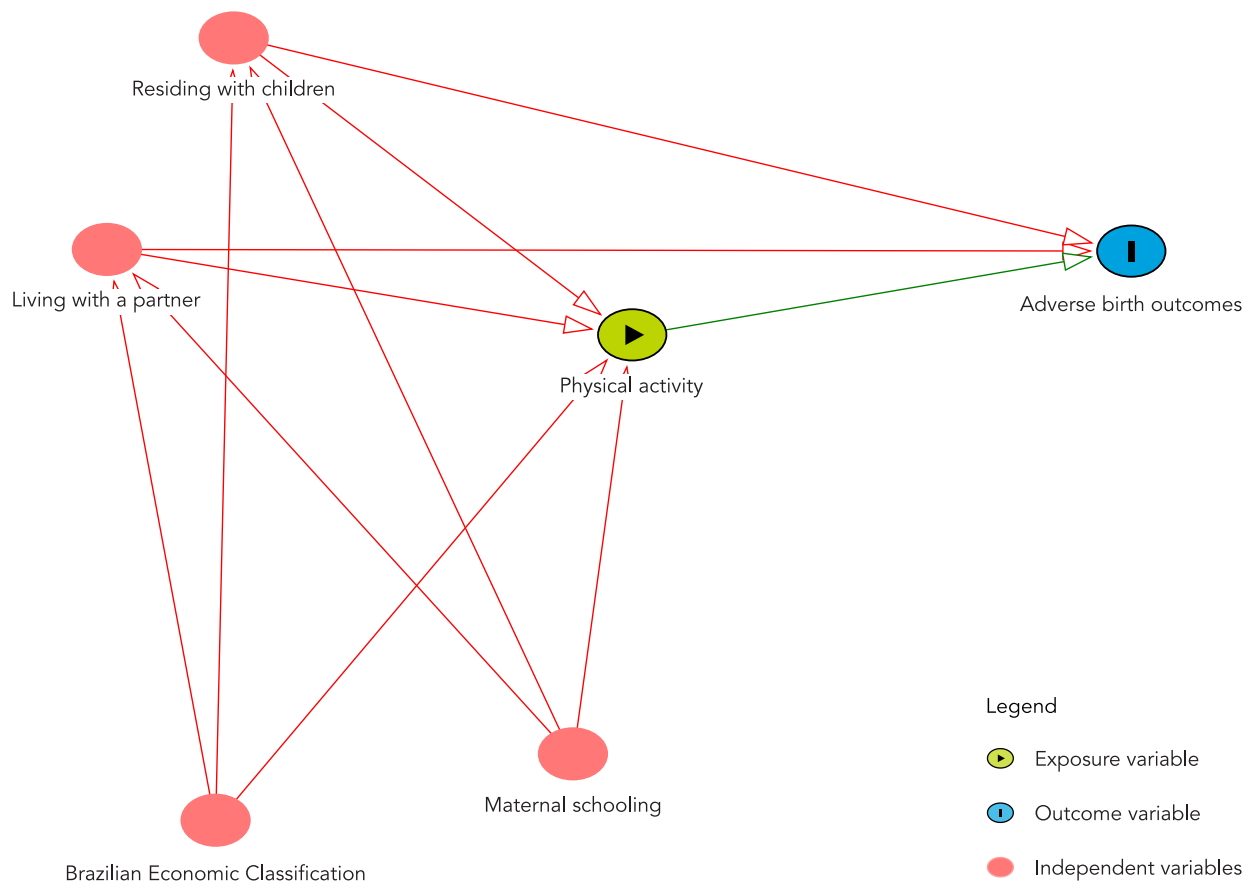

(protocol n. 223/2009) and all women gave written informed consent to participate.

\section{Results}

In the study sample, consisting of 1,380 pregnant women, most were $20-34$ years of age $(80.1 \%)$, had 9-11 years of schooling $(75.7 \%)$, were married or living with a partner $(79.5 \%)$, were not living with children (57.6\%), were primiparous $(51.5 \%)$, delivered vaginally (49.8\%), belonged to middle class $\mathrm{C}(66,5 \%)$ and had a family head engaged in unskilled manual labor or unemployed (72.4\%). Drug use was reported by $1.5 \%, 22.2 \%$ consumed alcohol, $4.3 \%$ smoked, $16.8 \%$ had hypertension, $3 \%$ diabetes, $28 \%$ were diagnosed with urinary tract infection, $10.9 \%$ reported vaginal bleeding, and $11.9 \%$ were hospitalized some time during the pregnancy. Levels of physical activity were: $39.7 \%$ low, $42.8 \%$ moderate, and $17.5 \%$ vigorous (Table 1).

No statistically significant association was observed between high $(\mathrm{RR}=0.94 ; 95 \% \mathrm{CI}$ : 0.54 1.63) or low level of physical activity $(\mathrm{RR}=0.88$;
95\%CI: 0.57-1.35; $\mathrm{p}=0.833$ ) and LBW, taking moderate as the reference. Neither was there any statistically significant association between high physical activity (RR $=0.86$; 95\%CI: $0.48-1.55)$ or low physical activity $(\mathrm{RR}=0.82$; 95\%CI: $0.53-1.26$; $\mathrm{p}=0.640$ ) and prematurity. High physical activity $(\mathrm{RR}=0.80 ; 95 \% \mathrm{CI}: 0.55-1.15)$ and low physical activity $(\mathrm{RR}=0.92 ; 95 \% \mathrm{CI}: 0.71-1.19 ; \mathrm{p}=0.456)$ were not associated with IUGR (Table 2).

Taking low physical activity as the reference, there were no associations between moderate or vigorous physical activity and LBW, PTB, or IUGR. No associations were observed between physical activity treated as a continuous variable, either in minutes or in MET-minutes/week, and adverse birth outcomes. A quadratic term for MET-minutes/week was non-significant. Even when considering physical activity in MET-minutes/week divided in tertiles, quartiles or quintiles, no association between physical activity and adverse birth outcomes was detected (Table 2). 
Table 1

Socioeconomic, clinical, and lifestyle characteristics of pregnant women studied in the city of São Luís, Maranhão State, Brazil, 2009-2011.

\begin{tabular}{|c|c|c|}
\hline Variable & $\mathrm{n}$ & $\%$ \\
\hline \multicolumn{3}{|l|}{ Schooling (years) } \\
\hline$\geq 12$ & 158 & 11.7 \\
\hline $9-11$ & 1,045 & 75.8 \\
\hline $5-8$ & 157 & 11.4 \\
\hline $0-4$ & 19 & 1.4 \\
\hline \multicolumn{3}{|l|}{ Occupation } \\
\hline Non-manual & 223 & 16.2 \\
\hline Skilled/Semiskilled manual & 157 & 11.4 \\
\hline Unskilled manual/Unemployed/Students & 1,000 & 72.5 \\
\hline \multicolumn{3}{|l|}{ Economic class } \\
\hline$A-B$ & 249 & 18.0 \\
\hline C & 919 & 66.6 \\
\hline D-E & 212 & 15.34 \\
\hline \multicolumn{3}{|l|}{ Maternal age (years) } \\
\hline $20-34$ & 1,116 & 80.9 \\
\hline$\geq 35$ & 95 & 6.9 \\
\hline$<20$ & 169 & 12.3 \\
\hline \multicolumn{3}{|l|}{ Living with a partner } \\
\hline No & 282 & 20.4 \\
\hline Yes & 1,098 & 79.6 \\
\hline \multicolumn{3}{|l|}{ Living with children } \\
\hline Yes & 585 & 42.4 \\
\hline No & 795 & 57.6 \\
\hline \multicolumn{3}{|l|}{ Parity } \\
\hline 1 & 711 & 51.5 \\
\hline$\geq 2$ & 660 & 48.5 \\
\hline \multicolumn{3}{|l|}{ Type of delivery } \\
\hline Vaginal & 687 & 49.8 \\
\hline Non-elective cesarean section & 382 & 27.7 \\
\hline Elective cesarean section & 311 & 22.5 \\
\hline \multicolumn{3}{|l|}{ Drug use } \\
\hline No & 1,357 & 98.5 \\
\hline Yes & 20 & 1.5 \\
\hline \multicolumn{3}{|l|}{ Alcohol } \\
\hline No & 1,073 & 77.8 \\
\hline Yes & 307 & 22.2 \\
\hline \multicolumn{3}{|l|}{ Maternal smoking } \\
\hline No & 1,321 & 95.7 \\
\hline Yes & 59 & 4.3 \\
\hline \multicolumn{3}{|l|}{ Hypertension } \\
\hline No & 1,147 & 83.2 \\
\hline Yes & 232 & 16.8 \\
\hline \multicolumn{3}{|l|}{ Diabetes } \\
\hline No & 1,338 & 97.0 \\
\hline Yes & 41 & 3.0 \\
\hline \multicolumn{3}{|l|}{ Urinary infection } \\
\hline No & 994 & 72.0 \\
\hline Yes & 385 & 28.0 \\
\hline \multicolumn{3}{|l|}{ Vaginal bleeding } \\
\hline No & 1,229 & 89.1 \\
\hline Yes & 150 & 10.9 \\
\hline \multicolumn{3}{|l|}{ Hospitalization } \\
\hline No & 1,215 & 88.1 \\
\hline Yes & 164 & 11.9 \\
\hline \multicolumn{3}{|l|}{ Physical activity } \\
\hline Low & 548 & 39.7 \\
\hline Moderate & 591 & 42.8 \\
\hline High & 241 & 17.5 \\
\hline
\end{tabular}


Adjusted analysis of the association between physical activity and preterm birth, low birth weight, and intrauterine growth restriction. São Luís, Maranhão State, Brazil, 2009-2011.

\begin{tabular}{|c|c|c|c|c|c|c|c|c|c|}
\hline \multirow[t]{2}{*}{ Variables } & \multicolumn{3}{|c|}{ Low birth weight } & \multicolumn{3}{|c|}{ Preterm birth } & \multicolumn{3}{|c|}{ Intrauterine growth restriction } \\
\hline & RR & $95 \% \mathrm{Cl}$ & p-value & RR & $95 \% \mathrm{Cl}$ & p-value & RR & $95 \% \mathrm{Cl}$ & $\mathrm{p}$-value \\
\hline Physical activity & & & 0.833 & & & 0.640 & & & 0.456 \\
\hline Moderate & 1.00 & & & 1.00 & & & 1.00 & & \\
\hline Low & 0.88 & $0.57-1.35$ & & 0.82 & $0.53-1.26$ & & 0.92 & $0.71-1.19$ & \\
\hline High & 0.94 & $0.54-1.63$ & & 0.86 & $0.48-1.54$ & & 0.80 & $0.55-1.15$ & \\
\hline Physical activity & & & 0.833 & & & 0.640 & & & 0.456 \\
\hline Low & 1.00 & & & 1.00 & & & 1.00 & & \\
\hline Moderate & 1.14 & $0.74-1.76$ & & 1.22 & $0.80-1.88$ & & 1.09 & $0.84-1.41$ & \\
\hline High & 1.07 & $0.61-1.89$ & & 1.05 & $0.58-1.92$ & & 0.87 & $0.60-1.26$ & \\
\hline Physical activity (continuous) & & & 0.995 & & & 0.485 & & & 0.087 \\
\hline MET & 0.99 & $0.99-1.00$ & & 1.00 & $0.99-1.00$ & & 0.99 & $0.99-1.00$ & \\
\hline \multicolumn{10}{|l|}{ Physical activity (continuous) } \\
\hline MET & 1.00 & $0.99-1.00$ & 0.715 & 1.00 & $0.99-1.00$ & 0.245 & 1.00 & $0.99-1.00$ & 0.904 \\
\hline MET2 & 1.00 & $1.00-1.00$ & 0.586 & 1.00 & $1.00-1.00$ & 0.271 & 1.00 & $1.00-1.00$ & 0.266 \\
\hline Physical activity (continuous) & & & 0.589 & & & 0.909 & & & 0.098 \\
\hline Minutes & 0.99 & $0.99-1.00$ & & 0.99 & $0.99-1.00$ & & 0.99 & $0.99-1.00$ & \\
\hline Physical activity (tertiles) & & & 0.934 & & & 0.652 & & & 0.254 \\
\hline First & 1.00 & & & 1.00 & & & 1.00 & & \\
\hline Second & 0.97 & $0.60-1.56$ & & 1.03 & $0.63-1.70$ & & 1.04 & $0.79-1.38$ & \\
\hline Third & 0.91 & $0.57-1.47$ & & 1.23 & $0.76-1.97$ & & 0.81 & $0.60-1.10$ & \\
\hline Physical activity (quartiles) & & & 0.916 & & & 0.634 & & & 0.451 \\
\hline First & 1.00 & & & 1.00 & & & 1.00 & & \\
\hline Second & 0.99 & $0.58-1.72$ & & 1.21 & $0.70-2.10$ & & 1.07 & $0.77-1.49$ & \\
\hline Third & 0.84 & $0.47-1.48$ & & 0.96 & $0.53-1.73$ & & 1.02 & $0.74-1.42$ & \\
\hline Fourth & 0.99 & $0.58-1.71$ & & 1.32 & $0.76-2.28$ & & 0.81 & $0.57-1.16$ & \\
\hline Physical activity (quintiles) & & & 0.776 & & & 0.648 & & & 0.571 \\
\hline First & 1.00 & & & 1.00 & & & 1.00 & & \\
\hline Second & 0.69 & $0.37-1.31$ & & 1.13 & $0.62-2.08$ & & 1.23 & $0.85-1.78$ & \\
\hline Third & 1.03 & $0.56-1.87$ & & 1.09 & $0.58-2.07$ & & 1.15 & $0.78-1.69$ & \\
\hline Fourth & 0.95 & $0.52-1.73$ & & 0.82 & $0.41-1.63$ & & 1.11 & $0.76-1.63$ & \\
\hline Fifth & 0.89 & $0.48-1.62$ & & 1.35 & $0.74-2.49$ & & 0.90 & $0.60-1.36$ & \\
\hline
\end{tabular}

95\% Cl: 95\% confidence interval; MET: metabolic equivalents; RR: rate ratio.

Note: models adjusted for maternal schooling, economic class, living with a partner, and living with children.

\section{Discussion}

The present study did not show any association between women's level of physical activity during the second trimester of pregnancy and adverse perinatal outcomes (LBW, PTB, and IUGR), regardless of level of activity, i.e., low or high, taking moderate as the reference. The findings are similar to those of a study in North Carolina from 2004 to 2007 23, in which pregnant women responded to a questionnaire by telephone, providing information on their physical activity in various domains (leisure-time, job-related, housework, and child and adult care), with no association detected between high physical activity in the first trimester and LBW or PTB.
The study also agrees with results of population-based surveys that failed to identify physical activity as a risk factor for adverse perinatal outcomes 24,25 . Two population-based cohort studies in 79,692 pregnant women in Denmark 24 between 1996 and 2002 and in 61,098 pregnant women in Norway 25 between 2000 and 2006 also showed no positive association between physical activity during pregnancy and prematurity. Instead, the studies actually showed a reduction of preterm delivery among women who had practiced some type of exercise during the second and third trimesters. The Norwegian study also showed a protective effect $(\mathrm{OR}=0.82$; $95 \% \mathrm{CI}$ : $0.73-0.91$ ) against prematurity in women that exercised 3 to 5 times a week. 
The results also agree with a randomized study of 105 sedentary primiparous pregnant women (mean age: $30.7 \pm 4.0$ years and pregestational body mass index (BMI): $23.8 \pm 4.3$ ), which concluded that aerobic and resistance exercises are not associated with preterm birth 26 . It should be noted that the women in the study were sedentary and therefore had no previous physical conditioning. Another study, which included pregnant women with hypertension and/ or previous preeclampsia, showed similar results, namely no increased risk of adverse maternal and neonatal outcomes, notably hypertensive complications, preterm birth, and low birth weight among women who had exercised during pregnancy 27 . In addition, a, systematic review indicated that physical activity during pregnancy had a protective effect against preeclampsia 28.

However, a cohort study in India in 546 rural pregnant women, assessing physical activity in various domains (job-related, leisure-time, caregiving, or housework) and during the three gestational trimesters detected an association between the highest tertile of physical activity and LBW 29.

A systematic review indicated that most studies did not detect an association between physical activity during pregnancy and LBW or PTB, but that some studies found an association between specific activities (e.g., climbing stairs or standing for long periods) and low birth weight and preterm birth 11. Our study did not ask pregnant women about specific physical activities. However, few women in our sample reached very high activity levels, and most physical activity in our sample probably involved household chores 30 . Thus, based on our data it seems that physical activity during pregnancy is not harmful to the fetus.

In the current study, a high percentage of pregnant women $(60.3 \%)$ were physically active in the second trimester. A large share of these women $(42.8 \%)$ reported moderate physical activity according to ACOG recommendations that might result in benefits for maternal-fetal health 7 , i.e., walking at least 30 minutes on 5 or more days a week.

A cross-sectional study in the city of Rio Grande, Rio Grande do Sul State, Brazil, in 2007 in a sample of 2,557 pregnant women showed that $32.8 \%$ were physically active 31 . The study excluded activities at school, on the job, and in the household, which may explain the lower percentage of physical activity compared to our study. In Pelotas, Rio Grande do Sul State, only $12.9 \%$ of a sample of 4,471 pregnant women practiced some type of leisure-time physical activity in any trimester of pregnancy 32 , indicating the impor- tance of considering on-the-job physical activity in pregnant women.

Until the 1990s, physical activity was discouraged for pregnant women 7 . Today there has been a change, with moderate physical activity recommended 7 , so that more women are physically active during pregnancy 31 . However, more pregnant women may be considered sedentary if physical activity is defined as planned exercising; in addition, a more sedentary routine may tend to increase in the third trimester 32 due to lack of time, fatigue, and discomfort with progression of the pregnancy 33 or a feeling of insecurity during physical activity 34 . Some studies indicate that pre-gestational physical exercise is an important predictor of higher levels of physical activity during pregnancy 32,35 .

The current study's strengths were its large sample size, low percentage of losses and refusals, and more precise calculation of gestational age based on a combination of gestational ultrasound before the 20th week and date of last menstruation.

The study's limitations include use of the short version of the IPAQ to assess physical activity. The short version does not distinguish between domains of physical activity (job-related, leisure-time, caregiving, or housework). In addition, physical activity was assessed only once in the second trimester, so it was not possible to verify the level throughout the pregnancy. Finally, no objective measure of physical activity was employed, which may produce measurement bias. Although objective measures of physical activity are less prone to error when compared to questionnaires 36 , they are still rarely used in population-based studies with large samples because of their high cost and complex logistics. Since data are collected on several days, close monitoring is required to avoid dropouts and supervise correct machine positioning. However, the IPAQ has been properly validated in the Portuguese language 15 and has been used previously to measure physical activity in pregnant women 37,38 . It is used internationally because it affords good stability, low cost, and acceptable accuracy in population studies 14. Furthermore, the results of the reproducibility study of type test / retest support the use of IPAQ to assess physical activity levels in different populations 14 .

Based on the current study's findings, physical activity of any level during the second trimester of pregnancy is not associated with adverse perinatal outcomes such as low birth weight, premature birth, or intrauterine growth restriction. 


\section{Contributors}

A. S. Rêgo contributed to the conception, elaboration, analysis, and final version for publication. M. T. S. S. B. Alves, C. C. C. Ribeiro, M. A. Barbieri, and A. A. M. Silva collaborated in the data analysis and final draft. R. F. L. Batista participated in the data analysis. H. Bettiol, V. C. Cardoso, and F. H. F. Loureiro contributed to the final draft.

\section{Acknowledgments}

We wish to thank the pregnant women that participated in the BRISA Prenatal Cohort in São Luís in 20102011 and the entire research team. The nested followup study was funded by CNPq, PRONEX, FAPESP, and FAPEMA.

\section{References}

1. Barker DJ, Eriksson JG, Forsen T, Osmond C. Fetal origins of adult disease: strength of effects and biological basis. Int J Epidemiol 2002; 31:1235-9.

2. Clayton PE, Cianfarani S, Czernichow P, Johannsson G, Rapaport R, Rogol A. Management of the child born small for gestational age through to adulthood: a consensus statement of the International Societies of Pediatric Endocrinology and the Growth Hormone Research Society. J Clin Endocrinol Metab 2007; 92:804-10.

3. Barker DJ. The long-term outcome of retarded fetal growth. Clin Obstet Gynecol 1997; 40:853-63.

4. Fitzhardinge PM, Steven EM. The small-for-date infant. II. Neurological and intellectual sequelae. Pediatrics 1972; 50:50-7.

5. Behrman RE, Butler AS. Preterm birth: causes, consequences and prevention. Washington DC: Institute of Medicine of the National Academies; 2007.

6. Silveira MF, Santos IS, Barros AJ, Matijasevich A, Barros FC, Victora CG. Increase in preterm births in Brazil: review of population-based studies. Rev Saúde Pública 2008; 42:957-64.

7. Committee of Obstetric Practice. ACOG committee opinion. Exercise during pregnancy and the postpartum period. Number 267, January 2002. American College of Obstetricians and Gynecologists. Int J Gynaecol Obstet 2002; 77:79-81.

8. Kramer MS, McDonald SW. Aerobic exercise for women during pregnancy. Cochrane Database Syst Rev 2006; (3):CD000180.

9. Clapp 3rd JF. The effects of maternal exercise on fetal oxygenation and feto-placental growth. Eur J Obstet Gynecol Reprod Biol 2003; 110 Suppl 1: S80-5.

10. Wolfe LA, Davies GA; School of Physical and Health Education, Department of Obstetrics and Gynaecology and Physiology, Queen's Univeristy. Canadian guidelines for exercise in pregnancy. Clin Obstet Gynecol 2003; 46:488-95.

11. Schlussel MM, Souza EB, Reichenheim ME, Kac G. Physical activity during pregnancy and maternalchild health outcomes: a systematic literature review. Cad Saúde Pública 2008; 24 Suppl 4:S531-44.

12. da Silva AA, Simoes VM, Barbieri MA, Cardoso VC Alves CM, Thomaz EB, et al. A protocol to identify non-classical risk factors for preterm births: the Brazilian Ribeirao Preto and Sao Luis prenatal cohort (BRISA). Reprod Health 2014; 11:79.

13. Associação Brasileira de Empresas de Pesquisa Critério de Classificação Econômica Brasil, CCEB, 2008. http://www.abep.org/Servicos/Download. aspx?id=05 (accessed on 19/Aug/2015).

14. Craig CL, Marshall AL, Sjostrom M, Bauman AE, Booth ML, Ainsworth BE, et al. International Physical Activity Questionnaire: 12-country reliability and validity. Med Sci Sports Exerc 2003; 35: 1381-95.

15. Matsudo S, Araujo T, Matsudo V, Andrade D, Andrade E, Oliveira LC, et al. International Physical Activity Questionnaire (IPAQ): study of validity and reliability in Brazil. Rev Bras Ativ Fís Saúde 2001; 6:5-18. 
16. International Physical Activity Questionnaire. Guidelines for data processing and analysis of the International Physical Activity Questionnaire (IPAQ) - short and long forms, 2004. http://www. ipaq.ki.se/scoring.pdf (accessed on 23/Nov/2012).

17. Kramer MS, McLean FH, Olivier M, Willis DM, Usher RH. Body proportionality and head and length 'sparing' in growth-retarded neonates: a critical reappraisal. Pediatrics 1989; 84:717-23.

18. Kramer MS, Platt RW, Wen SW, Joseph KS, Allen A, Abrahamowicz M, et al. A new and improved population-based Canadian reference for birth weight for gestational age. Pediatrics 2001; 108:E35.

19. Verburg BO, Steegers EA, De Ridder M, Snijders RJ, Smith E, Hofman A, et al. New charts for ultrasound dating of pregnancy and assessment of fetal growth: longitudinal data from a populationbased cohort study. Ultrasound Obstet Gynecol 2008; 31:388-96.

20. Zou G. A modified Poisson regression approach to prospective studies with binary data. Am J Epidemiol 2004; 159:702-6.

21. Textor J, Hardt J, Knuppel S. DAGitty: a graphical tool for analyzing causal diagrams. Epidemiology 2011; 22:745.

22. Takito MY, Benicio MH. Physical activity during pregnancy and fetal outcomes: a case-control study. Rev Saúde Pública 2010; 44:90-101.

23. Jukic AM, Evenson KR, Daniels JL, Herring AH, Wilcox AJ, Hartmann KE. A prospective study of the association between vigorous physical activity during pregnancy and length of gestation and birthweight. Matern Child Health J 2012; 16: 1031-44.

24. Juhl M, Andersen PK, Olsen J, Madsen M, Jorgensen T, Nohr EA, et al. Physical exercise during pregnancy and the risk of preterm birth: a study within the Danish National Birth Cohort. Am J Epidemiol 2008; 167:859-66.

25. Owe KM, Nystad W, Skjaerven R, Stigum H, Bo K. Exercise during pregnancy and the gestational age distribution: a cohort study. Med Sci Sports Exerc 2012; 44:1067-74.

26. Haakstad LA, Bo K. Exercise in pregnant women and birth weight: a randomized controlled trial. BMC Pregnancy Childbirth 2011; 11:66.

27. Kasawara KT, Burgos CS, do Nascimento SL, Ferreira NO, Surita FG, Pinto ESJL. Maternal and perinatal outcomes of exercise in pregnant women with chronic hypertension and/or previous preeclampsia: a randomized controlled trial. ISRN Obstet Gynecol 2013; 2013:857047.
28. Kasawara KT, do Nascimento SL, Costa ML, Surita FG, Silva JL. Exercise and physical activity in the prevention of pre-eclampsia: systematic review. Acta Obstet Gynecol Scand 2012; 91:1147-57.

29. Dwarkanath P, Muthayya S, Vaz M, Thomas T, Mhaskar A, Mhaskar R, et al. The relationship between maternal physical activity during pregnancy and birth weight. Asia Pac J Clin Nutr 2007; 16: 704-10.

30. Takahasi EHM, Alves MTSSB, Alves GS, Silva AAM, Batista RFL, Simões VMF, et al. Mental health and physical inactivity during pregnancy: a cross-sectional study nested in the BRISA cohort study. Cad Saúde Pública 2013; 29:1583-94.

31. Dumith SC, Domingues MR, Mendoza-Sassi RA, Cesar JA. Physical activity during pregnancy and its association with maternal and child health indicators. Rev Saúde Pública 2012; 46:327-33.

32. Domingues MR, Barros AJ. Leisure-time physical activity during pregnancy in the 2004 Pelotas Birth Cohort Study. Rev Saúde Pública 2007; 41:173-80.

33. Ribeiro CP, Milanez H. Knowledge, attitude and practice of women in Campinas, Sao Paulo, Brazil with respect to physical exercise in pregnancy: a descriptive study. Reprod Health 2011; 8:31.

34. Hegaard HK, Kjaergaard H, Damm PP, Petersson K, Dykes AK. Experiences of physical activity during pregnancy in Danish nulliparous women with a physically active life before pregnancy. A qualitative study. BMC Pregnancy Childbirth 2010; 10:33.

35. Ning Y, Williams MA, Dempsey JC, Sorensen TK, Frederick IO, Luthy DA. Correlates of recreational physical activity in early pregnancy. J Matern Fetal Neonatal Med 2003; 13:385-93.

36. Harrison CL, Thompson RG, Teede HJ, Lombard CB. Measuring physical activity during pregnancy. Int J Behav Nutr Phys Act 2011; 8:19.

37. Harizopoulou VC, Kritikos A, Papanikolaou Z, Saranti E, Vavilis D, Klonos E, et al. Maternal physical activity before and during early pregnancy as a risk factor for gestational diabetes mellitus. Acta Diabetol 2010; 47 Suppl 1:83-9.

38. Marshall ES, Bland H, Melton B. Perceived barriers to physical activity among pregnant women living in a rural community. Public Health Nurs 2013; 30:361-9. 


\section{Resumo}

Investigou-se a associação entre atividade física durante o segundo trimestre gestacional e os desfechos perinatais adversos: baixo peso ao nascer (BPN), nascimento pré-termo (NPT) e restrição de crescimento intrauterino (RCIU). Foi utilizada amostra da coorte BRISA, São Luís, Maranhão, Brasil, que incluiu mulheres com gravidez única, idade gestacional de 22 a 25 semanas confirmada por ultrassonografia obstétrica realizada com $<20$ semanas, reentrevistadas nas primeiras 24 horas após o parto $(n=1.380)$. O nível de atividade física foi medido pelo Questionário Internacional de Atividade Física (IPAQ), versão curta, $e$ categorizado em alto, moderado e baixo. Gráfico acíclico direcionado (DAG) foi utilizado para identificar ajuste mínimo para o controle de confundimento. Nível alto de atividade física não foi associado ao BPN $(R R=0.94$; IC95\%: 0,54-1,63), NPT $(R R=0,86$; IC95\%: 0,48-1,54) ou RCIU (RR=0,80; IC95\%: 0,55-1,15). Os resultados fortalecem a hipótese de que a prática de atividade física na gestação não parece resultar em desfechos adversos ao nascimento.

Gravidez; Atividade Motora; Recém-Nascido de Baixo Peso; Prematuro

\section{Resumen}

Se investigó la asociación entre actividad física durante el segundo trimestre gestacional y los desenlaces perinatales adversos: bajo peso al nacer (BPN), nacimiento pretérmino (NPT) y restricción de crecimiento intrauterino (RCIU). Se utilizó una muestra de la cohorte BRISA, São Luís, Maranhão, Brasil, que incluyó mujeres con un embarazo único, edad gestacional de 22 a 25 semanas, confirmada por ultrasonografía obstétrica realizada con $<20$ semanas, reentrevistadas en las primeras 24 horas tras el parto $(n=1.380)$. El nivel de actividad física fue medido por el Cuestionario Internacional de Actividad Física (IPAQ), versión corta, y categorizado en alto, moderado y bajo. El gráfo acíclico dirigido (DAG) se utilizó para identificar un ajuste mínimo para el control de confusores. Un nivel alto de actividad física no se asoció al BPN (RR = 0,94; IC95\%: 0,54-1,63), NPT (RR =0,86; IC95\%: 0,48-1,54) o RCIU $(R R=0,80$; IC95\%: 0,55-1,15). Los resultados fortalecen la hipótesis de que la práctica de actividad física en la gestación no parece resultar en desenlaces adversos al nacimiento.

Embarazo; Actividad Motora; Recién Nacido de Bajo Peso; Prematuro
Submitted on $03 /$ Jun/2015

Final version resubmitted on 31/Dec/2015 Approved on 05/Jan/2016 